\title{
UM COLÉGIO, UMA DISTINÇÃO: O COLÉGIO AURORA DE CAÇADOR, SANTA CATARINA, EM TEMPOS DE NACIONALIZAÇÃODO ENSINO ${ }^{1}$
}

\author{
Ana Laura Tridapalli \\ UDESC
}

Maria das Dores Daros

UFSC

\section{RESUMO}

O presente artigo discorre sobre o Colégio Aurora de Caçador, Santa Catarina,durante a década de 1930, sob a administração do casal de italianos Dante e Albina Mosconi.Nestas páginas discutiremos algumas questões analisadas na pesquisa de mestrado sobre esta instituição escolar, tais como, a distinção desse educandário em tempos de nacionalização do ensino e a mudança de trajetória dos alunos egressos. Nossa análise é sócio-histórica, dialogando principalmente com o sociólogo francês Pierre Bourdieu. Como fontes, utilizamos iconografias, entrevistas, periódicos e documentos institucionais.

Palavras-chave: Colégio Aurora, Caçador, nacionalização, distinção, trajetórias

\section{A COLLEGE, A DISTINCTION: THE AURORA SCHOOL DE CAÇADOR, SANTA CATARINA, IN TIMES OF EDUCATION NATIONALIZATION}

\begin{abstract}
This article discusses the Aurora Scholl of Caçador, Santa Catarina, during the 1930s, under the administration of the Italian couple Dante and Albina Mosconi. In these pages we will discuss some issues analyzed in this master's research on the school, such as the distinction that breed in times of nationalization of education and the changing trajectory of alumni. Our analysis is sociohistorical, talking mainly with the French sociologist Pierre Bourdieu. How to use iconography sources, interviews, journals and institutional documents
\end{abstract}

Keywords: Aurora School, Caçador, nationalization, distinction, trajectories

\section{Introdução}

O Colégio Aurora, de Caçador, fundado em 1928 pelo casal de italianos Dante e Albina Mosconi, foi o primeiro educandário a possuir a equiparação de três cursos de nível secundário no oeste do estado de Santa Catarina.

Após uma curta passagem pelo estado do Rio Grande do Sul, o casal, que desembarcara no Brasil em 1923, migra para Caçador, Santa Catarina, que, na época, ainda não era um município e suas terras, pouco habitadas. A região figurava no antigo território contestado pelos estados do Paraná e de Santa Catarina. Após um arrastado processo judicial e até mesmo um conflito armado, conhecido como a Guerra do Contestado (19121916), os limites são demarcados em 1917, viabilizando o processo de colonização da região. 
A construção da estrada de ferro São Paulo-Rio Grande e as empresas colonizadoras atraíram muitos moradores, principalmente vindos do Rio Grande do Sul. Incentivados pela boa qualidade da terra e pela oportunidade de novos negócios, como escreve Nilson Thomé:

Os novos habitantes, na maioria descendentes de imigrantes alemães, italianos, poloneses, e árabes, desenvolviam os mais diversos ramos de atividades, ligados à indústria, ao comércio, à prestação de serviços e à agricultura, mas sempre tendo por base a exploração madeireira (...). (THOMÉ, 1993, p.7).

Em 1928 o casal Mosconi chega a Rio Caçador e com a ajuda de moradores, coloca em prática um sonho antigo: fundar um colégio onde Albina pudesse exercer sua formação como professora.

No início, funcionava no Colégio Aurora o curso primário, o de Guarda-Livros e o Normal $^{2}$. Os recursos eram poucos e o próprio espaço físico era precário. Porém, em 1930, ergue-se um novo prédio de madeira, que passará a abrigar alunos em regime de internato. As modificações na estrutura ocasionaram o pedido de equiparação dos cursos Ginasial e Normal, às Inspetorias de Instrução Pública Federal e Estadual, respectivamente.

Com poucas condições, o casal Mosconi conseguiu formar diversos alunos, que não pertenciam somente à localidade de Caçador, mas eram provenientes de toda a parte do meio oeste catarinense e também de cidades do Rio Grande do Sul e do Paraná. Por tudo isso, o casal ainda é muito lembrado pela população local.

A importância do Colégio para a cidade foi tão significativa que, quando no dia 12 de fevereiro de 1934 o Colégio Aurora consegue equiparar seu curso ginasial ao Ginásio Pedro II do Rio de Janeiro, em menos de duas semanas, a 22 de fevereiro, o interventor Aristiliano Ramos cria o município de Caçador. Por isso, para muitos, o fato de Caçador sediar o primeiro Ginásio da região foi fator decisivo para a emancipação política do município, o que só foi possível graças aos esforços do casal de italianos.

Mesmo com a rápida passagem do casal pela administração da escola (1928-1938), sua influência esteve marcada em uma geração de alunos do Colégio Aurora. Além da escassez financeira que o casal vinha enfrentando, outro fator de grande relevância fez com que Dante Mosconi fosse obrigado a vender o seu colégio: a questão da nacionalização do ensino proposta pelo governo Vargas. Nesse contexto, Dante e Albina Mosconi foram impedidos de continuar à frente da sua instituição, pois se negaram a naturalizarem-se brasileiros. Muito interessante a resposta de Dante Mosconi ao ser perguntado pelo então interventor Nereu Ramos, acerca do porquê da negativa: "Como poderei ensinar patriotismo aos meus alunos, se renegar a minha Pátria?” (RAISEL, 1984, p.12).

O Estado Novo teve como meta principal a política de nacionalização do Estado brasileiro. Um Estado que, até então, era formado por muitas e diversas nacionalidades, devido às constantes imigrações que se avolumavam principalmente a partir do século XIX. Sob tal perspectiva, a região sul do Brasil torna-se o centro da política educacional varguista, haja vista que a sua população era composta por uma grande quantidade de imigrantes europeus, na sua maioria alemães, italianos e poloneses.

Segundo Seyferth (1981), a partir de 1937, a Campanha de Nacionalização esteve sob a ótica da ditadura do Estado Novo, com um governo autoritário e nacionalista. $\mathrm{O}$ programa de ação da referida campanha tinha como premissa erradicar as influências estrangeiras atuantes, principalmente nos três estados do sul, e incutir nas populações de origem europeia (especialmente alemã, polonesa e italiana) o sentimento de brasilidade.

Para Getúlio Vargas, a formação de uma homogeneidade e, principalmente de uma 
identidade brasileira, vai se concentrar no campo educacional, sendo ele o responsável pela constituição do novo cidadão brasileiro. Nesse sentido, escreve José Baia Horta, (1993, p.293) "a partir de 1937, o Estado fixa um objetivo bem preciso para suas intervenções: utilizar a educação como instrumento para inculcar na infância e na juventude os princípios do Estado Novo, servindo assim como arma ideológica".

A política de nacionalização chega também ao estado de Santa Catarina, tendo na figura do interventor federal Nereu Ramos o seu principal comandante. No período em questão, muitas escolas foram fechadas nas áreas de colonização italiana e alemã; professores foram impedidos de lecionar, justamente pelo fato de não conhecerem corretamente o idioma nacional. A esse respeito, Campos escreve:

No programa político que o [Nereu Ramos] levou ao poder público e nas reformas educacionais que ocorreram durante a campanha de nacionalização do ensino, a educação vinculou-se a um projeto mais amplo, que tinha como alvo promover a unificação do uso da língua e dos costumes (CAMPOS, 1992, p.145).

Política extremamente autoritária, não se restringiu apenas às escolas, mas proibiu também o uso dos idiomas estrangeiros no próprio cotidiano das colônias imigrantes. $\mathrm{O}$ que ocasionou não só um desconforto, mas também certo medo na vida daquelas pessoas pelas constantes perseguições - e mesmo punições - não só do poder público, mas da própria sociedade, que passou a tratá-las como desiguais, diferentes, estrangeiros na terra que haviam adotado como sua. Conforme ressalta Marlene de Fáveri,

Naqueles anos, estratégias governamentais arvoraram-se na produção de sujeitos que temessem um 'outro', ou aquele que, na contingência das relações, era inimizado por conta de sua origem étnica. Ao mesmo tempo, pretenderam que se constituíssem como "bons brasileiros" e patriotas não sem intolerâncias, silêncios, violências, astúcias [...] (FAVERI, 2004, p.38).

O Estado Novo, portanto, pretendia a assimilação compulsória ou forçada das minorias, através de uma legislação específica, que colocou à margem da lei a maior parte das instituições (sociedades assistenciais, imprensa, escola, etc.), consideradas estrangeiras (VIRTUOSO, 2008). Por isso, os diretores do Colégio Aurora foram coagidos a vender a sua instituição educacional, já que, de acordo com a nova legislação, os diretores de escolas teriam que ser brasileiros.

Em 1936, os Irmãos Maristas, vindos do Rio Grande do Sul, mostraram interesse em comprar o Colégio, iniciando as negociações. A Congregação dos Irmãos Maristas fixou-se no Rio Grande do Sul desde o início do século XX, onde fundaram vários colégios e instituições ligadas ao ensino, como o Colégio Santa Maria e o Colégio do Rosário, em Porto Alegre.Há muito se via a intenção desses irmãos de expandirem pelo território catarinense e também paranaense suas instituições escolares, segundo escreve RiolandoAzzi: Essa expansão da obra foi o resultado do projeto visando à consolidação da obra marista tanto na região paulista como no extremo sul do país. (AZZI, 1997, p. 409).

A Congregação dos Irmãos Maristas tem sua origem na França, no início do século XIX, com Marcelino Champagnat, o que explica o fato de a maior parte dos irmãos serem dessa nacionalidade. O que nos chamada atenção é que a questão do estrangeirismo, naquele momento, não foi um problema para que os irmãos assumissem a direção do Colégio Aurora ${ }^{3}$. 


\section{Um colégio distinto: os cursos oferecidos na década de 1930}

Em 1929, Dante Mosconi fundou o Tiro de Guerra $\mathrm{n}^{\circ}$ 568, com sede no próprio colégio. A questão étnica não foi um obstáculo para o alcance da licença, pois os Tiros de Guerra são instituições subvencionadas pelo exército e uma das prerrogativas é a nacionalidade brasileira. Mas a instalação de um polo do serviço militar no meio oeste catarinense facilitaria a vida de muitos jovens agricultores em idade de alistamento, ainda mais porque o Batalhão localizava-se dentro de uma instituição escolar, o que permitiria a eles a continuação de seus estudos.

A partir da instalação do Tiro de Guerra $n^{\circ} 568$ (figura 1), muitos rapazes de 18 anos ou mais se mudaram para Caçador, a fim de concluirem o serviço militar, com o que eles compartilhariam os estudos no Colégio Aurora no período vespertino, enquanto nas manhãs dedicariam o tempo aos treinamentos do Tiro.

Figura 1 - Batalhão do Tiro de Guerra 568 anexo ao Colégio Aurora - Anos 30

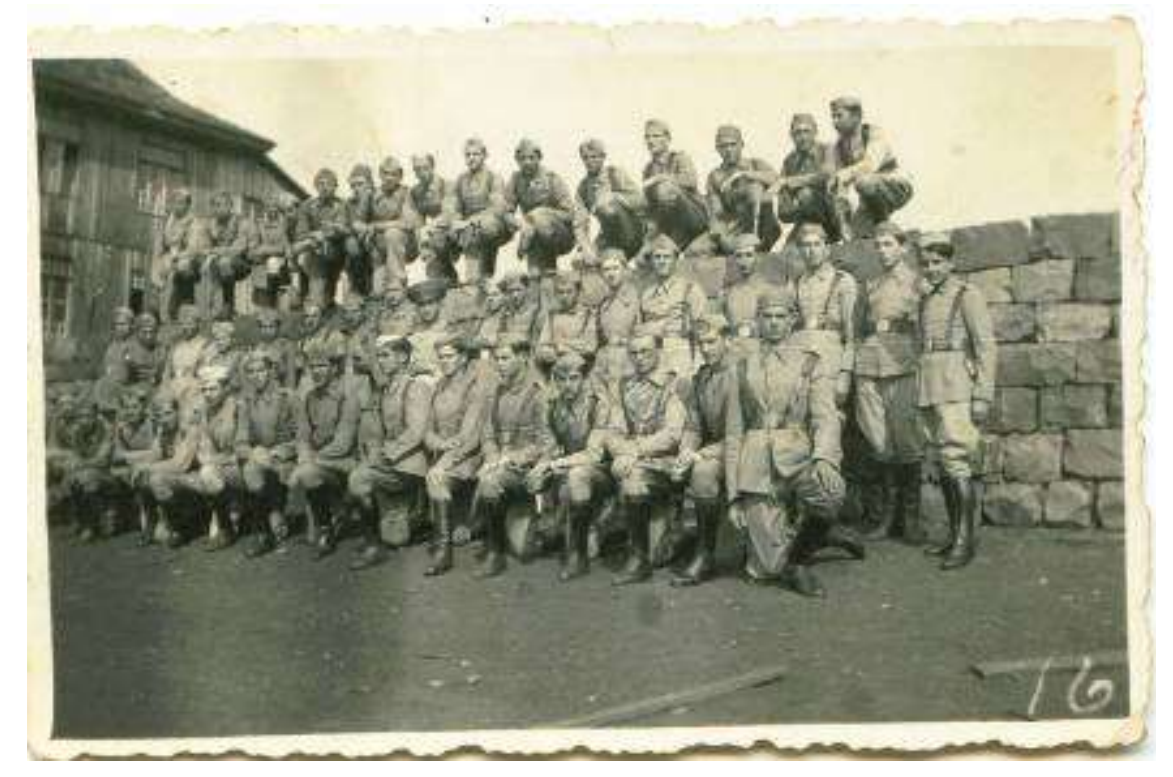

Fonte: Acervo de Nilson Thomé, [193_]

Mas a iniciativa de criar um Tiro de Guerra vinculado ao exército ajudaria a confirmar que a intenção dos diretores do colégio era a formação de cidadãos brasileiros, já que esses jovens descendentes de imigrantes europeus seriam formados para ingressar nas Forças Armadas do Brasil. Mesmo tendo um diretor italiano, o Colégio Aurora afirmava, com a anexação de um Tiro de Guerra, que o seu currículo não tinha como intenção disseminar a cultura italiana.

Em 1931 foi oficializado o Curso de Guarda-Livros do Instituto Comercial do Rio de Janeiro. Pelo Decreto $n^{\circ}$ 20.158, de 30 de junho de 1931, organizou-se o Ensino Comercial nos níveis médio e superior e regulamentou-se a profissão de contador. Segundo Romanelli, pelo decreto, os cursos ficaram estruturados da seguinte forma: 
Cursos médios: $1^{\circ}$ ciclo - curso propedêutico, de 3 anos; curso de auxiliar de comércio, de 2 anos; $2^{\circ}$ ciclo - cursos técnicos de secretários, de 1 ano; guarda-livros, de 2 anos; administrador-vendedor, de 2 anos; atuário, de 3 anos; perito contador, de 3 anos.

Curso superior: curso superior de finanças, de 3 anos (ROMANELLI, 1985, p. 138).

No Colégio Aurora só funcionava o curso de Guarda-Livros que, como é possível ler na citação anterior, era um curso do $2^{\circ}$ ciclo do nível médio com uma duração de dois anos. Para o ingresso nos cursos do $2^{\circ}$ ciclo era exigida a conclusão num dos cursos do $1^{\circ}$ ciclo ou da $5^{\mathrm{a}}$ série do curso secundário fundamental. Sendo um curso profissionalizante, pela legislação da época, o curso de Guarda-Livros tinha o caráter terminal, não possibilitando o acesso ao curso superior.

A formação da primeira turma de "Guarda-Livros", sob a responsabilidade do Instituto Comercial do Rio de Janeiro, ocorreu em $1930^{4}$. A turma não era apenas a primeira a ser formada no Colégio Aurora, mas também a primeira turma de contadores do oeste catarinense. Os contadores formados eram Luiz Driessen Sobrinho, Guilherme Joaquim e IzaltinoRaisel. Essa formação tinha muita importância naqueles tempos, haja vista o grande número de indústrias ligadas ao ramo madeireiro que necessitavam do técnico em contabilidade para administrar suas finanças.

Em 1932 Dante Mosconi conseguiu ainda a criação da Escola de Instrução Militar conforme registrado pelo jornal: "a fim de proporcionar aos seus alunos o direito de reservistas do Exército, o dr. Dante Mosconi, digno diretor do Colégio Aurora, que funciona no distrito de Santelmo, acaba de obter licença das autoridades competentes, para a criação, naquele estabelecimento, de uma Escola de Instrução Militar, que tomou o número 354" (O COMÉRCIO, 1932, p. 1).

Desde 1930, o Estado brasileiro, que estava nas mãos do presidente Getúlio Vargas, aproximava-se dos ideais militares. A nação precisava de corpos fortes, viris, disciplinados e que, acima de tudo, amassem sua pátria. A partir de 1937, com a outorgação do Estado Novo, a política de nacionalização é intensificada pelo governo ditatorial. De tal sorte que foi relegada aos militares toda a prática de exercícios físicos presente nas escolas brasileiras, bem como a formação de alunos soldados. Segundo Baía Horta

Os militares contentar-se-ão com duas iniciativas bem mais limitadas, a serem realizadas sob sua iniciativa e direção: a implantação da educação física escolar e a extensão da Instrução Pré Militar aos alunos menores de dezesseis anos, inscritos nos estabelecimentos de ensino primário e secundário (HORTA, 1993, p. 30).

Em 1939 torna-se obrigatória a instrução pré-militar para alunos menores de 16 anos, sendo que todo estabelecimento de ensino primário, secundário ou profissional seria obrigado a criar e manter uma escola de Instrução Pré-Militar. Antes mesmo de se tornar Lei, Dante Mosconi instalara no Ginásio Aurora a instrução militar (Figura 2). O ex-aluno Ângelo Barrichello lembra:

Era difícil. Inclusive era obrigado durante a guerra, todo ginasiano, não interessava a idade, fazer um curso pré-militar. A gente praticava a marcha, progressão militar, montar e desmontar fuzil, e não importava a idade. Então, o cidadão ao receber esse certificado ele podia servir ao exército, mesmo não tendo 18 anos. Chamava-se CIP, Centro de 
Instrução Pré-Militar. Por isso eu comecei a fazer Tiro de Guerra com 16 anos (BARRICHELLO, 2006, p. 2).

A implantação de centros de Instrução Militar nas escolas brasileiras, possuindo um caráter totalmente autoritário, justificava-se pelo constante imaginário do "perigo inimigo". No primário, o uso de armas não era empregado, mas as regras de disciplina, hierarquia e organização do exército já se faziam presentes nas aulas de Educação Física. Para Horta (1993, p. 64), a "preparação militar pode ser apontada como uma das principais razões pelas quais uma determinada sociedade integra em maior ou menor grau, a educação física em seu sistema educativo".

Figura 2 - Turma de Formandos da Escola de Instrução Militar 354 do ano de 1932

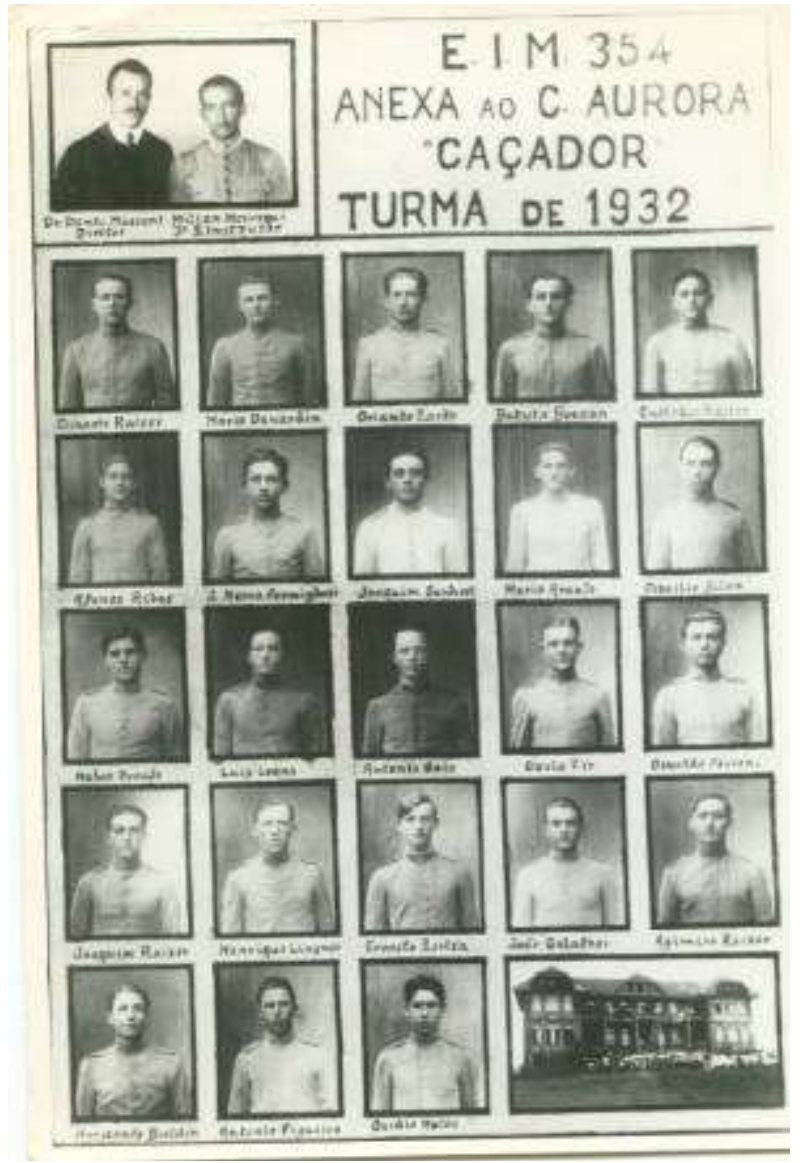

Fonte: Acervo de Nilson Thomé, 1932.

O ensino da Educação Física aparece pela primeira vez na Lei do Ensino Secundário de 1931, no Art. 9, que prescreve: "Durante o ano letivo haverá ainda nos estabelecimentos de ensino secundário, exercícios de educação física obrigatórios para todas as classes" (BICUDO, 1942, p. 10).

Desde a obrigatoriedade do ensino da educação física, os militares tomaram para si a prática da disciplina nas escolas brasileiras. Na verdade, existia todo um alinhamento de ideologias entre o governo varguista e os militares. Com o imaginário de defender o Brasil do inimigo externo em caso de guerra, ou mesmo do interno - comunistas e estrangeiros -, 
incutir-se-á nos discursos oficiais a importância da formação de um contingente de "soldados" prontos para proteger a nação.

Assim, naquele momento histórico, a Educação Física realmente serviu como uma preparação militar, não se restringindo somente do culto ao corpo. A disciplina formou os soldados para a pátria, ainda jovens meninos que, com 12 e 13 anos, já aprendiam a lógica da guerra, o montar e desmontar fuzil.

Após a oficialização do Curso de Guarda-Livros e a criação da Escola de Instrução Pré Militar, os diretores Dante e Albina buscaram a equiparação dos cursos Normal e Ginasial à Escola Normal Catarinense e ao Colégio Pedro II, respectivamente. Segundo Ernesto Faoro ${ }^{5}$, Dona Albina viajava quinzenalmente ao Rio de Janeiro para conseguir tal liberação, pois o Ginásio, para ser equiparado, deveria se ajustar às normas do Ginásio Pedro II, da capital federal. A Escola Normal, por sua vez, como estava sob a legislação estadual, deveria ser equiparada à Escola Normal Catarinense, localizada em Florianópolis.

Em dezembro de 1933, o Curso Normal do Colégio Aurora, pelo decreto 436, consegue a equiparação à Escola Normal Catarinense, e o Ginásio, em fevereiro de 1934, foi equiparado ao Colégio Pedro II. Os dois acontecimentos foram de extrema importância não só para o colégio, mas principalmente para a emancipação política do município, que até então era somente um distrito pertencente à cidade de Porto União.

Até 1938 Dante e Albina continuaram dirigindo o Colégio Aurora, mas os problemas financeiros aumentaram e a solução encontrada foi a venda. A Congregação Marista, que ainda não possuía nenhuma instituição educacional em Santa Catarina, se interessou pela compra. $\mathrm{O}$ processo de negociações contou até mesmo com o interventor estadual, Nereu Ramos, que pleiteava a presença dos Irmãos Maristas na direção do Abrigo de Menores na capital do Estado.

A negociação ${ }^{6}$ deixa claro que havia outro problema envolvendo a venda do Colégio Aurora: a questão da nacionalização do ensino. Nesse contexto, Dante e Albina Mosconi foram proibidos de continuar à frente da sua instituição, uma vez que se negaram a naturalizarem-se brasileiros.

Não encontramos, em toda a pesquisa, fatores que denunciem uma postura étnica italiana do casal dentro do colégio. Pelo contrário: o que os dados mostraram foi justamente uma preocupação em relação à formação de cidadãos brasileiros. A presença do Tiro de Guerra e a criação da Escola de Instrução Militar registram a aliança com o exército na educação de novos soldados.

\section{Mudando Trajetórias: o Ensino Secundário do Colégio Aurora nos anos 1930}

O Colégio Aurora foi o primeiro estabelecimento do oeste catarinense a oferecer o ensino secundário em nível ginasial. Sua importância se evidencia sobremaneira por ser ele o responsável pela formação dos novos dirigentes de uma sociedade em pleno processo de criação. Estudar em um curso ginasial e normal, naqueles tempos, era privilégio para poucos, principalmente no estado de Santa Catarina, onde todos os estabelecimentos que ofereciam esse nível de ensino eram privados e, entre as Escolas Normais ${ }^{7}$, somente duas eram gratuitas. Bittencourt chama atenção para a forte elitização do ensino secundário no Brasil:

Entre nós, o ensino secundário representava, igualmente, um meio de preservar privilégios e manter a separação entre a elite identificada com um mundo branco europeu e o restante da população, composta de mestiços, negros, e índios. Eram cursos reservados a alunos em condições econômicas favoráveis, conservando-se, sempre, como um curso pago (...) além de ser um curso exclusivamente reservado aos jovens do sexo masculino (BITTENCOURT, 1993, p.58). 
O curso ginasial tinha o caráter propedêutico, garantindo aos seus formandos o ingresso no curso superior. As estratégias educacionais do casal de italianos nessa instituição ajudam a entender o processo de construção da cidade de Caçador e região. Nesse sentido, as reflexões sociológicas de Pierre Bourdieu nos permitem entender que as escolas diferenciam-se pela forma como respondem às demandas de capital cultural de grupos sociais específicos, que têm expectativas diferentes em relação à educação escolar.

As práticas escolares têm operado exclusões de grupos sociais significativos, devido às suas identidades serem tidas como periféricas pelos padrões sociais vigentes. Dessa forma, as desigualdades sociais e as discriminações étnicas, religiosas e de gênero são fabricadas também pelo modo como as escolas estruturam e fazem circular os saberes.

A presente pesquisa registrou no Colégio Aurora muitas matrículas de imigrantes, em sua maioria italianos. Eles eram descendentes das antigas famílias que chegaram ao estado do Rio Grande Sul ainda no século XIX. Com a escassez de terras, muitas dessas famílias migraram para o oeste catarinense a partir da década de 1920. Os colonos, como será denominado esse grupo étnico, se dividiam em agricultores, comerciantes e industriais.

Muitos optaram pelas vilas de Santelmo e Rio Caçador, justamente pela proximidade com o Colégio Aurora, aonde seus filhos viriam a estudar. Assim, o capital econômico acumulado por tais famílias seria utilizado para a aquisição de capital escolar.

Mesmo os imigrantes que não moravam em Caçador poderiam matricular seus filhos no colégio, já que o mesmo possuía regimes de externato e internato, permitindo, assim, o abrigo de estudantes vindos das mais diversas cercanias. No Relatório de Classificação do Colégio Aurora de 1938, apresentado à divisão do Ensino Secundário,o Ginásio atendia os alunos em idade ginasial dos municípios catarinenses de Cruzeiro, Xanxerê, Canoinhas, Curitibanos, Lages, Porto União e Campos Novos; os paranaenses de Clevelândia, Palmas e de União da Vitória, os sul-rio-grandenses de Lagoa Vermelha, Boa Vista do Erechim, Barros, etc. (RELATÓRIO...,1938).

A escolha dos imigrantes em matricular seus filhos no Colégio Aurora se aproxima da discussão de Bourdieu acerca da aprendizagem tardia. O sociólogo francês nos ajuda a pensar a importância da acumulação de capital econômico, social e cultural na família e em outras instituições sociais para o êxito escolar. Para Bourdieu, existem duas formas de obtenção da cultura: a aprendizagem total, própria das elites, acumulada pela família e aprimorada pela escolarização e a aprendizagem tardia, específica das classes médias e populares, adquirida especialmente nas instituições escolares.

Assim,

[...] a aprendizagem implica o trabalho pedagógico como trabalho de inculcação que deve durar o bastante para produzir uma formação durável; isto é, um habitus como produto da interiorização dos princípios de um arbitrário cultural capaz de perpetuar-se após a cessação da aprendizagem e por isso de perpetuar nas práticas os princípios do arbitrário interiorizado (BOURDIEU, 1970, p. 44).

O Colégio Aurora era o lugar onde esses imigrantes poderiam garantir um futuro melhor a seus filhos. O grupo se enquadra no que Bourdieu chama de classes médias e populares: mesmo os que possuíam um maior volume de capital não chegavam a caracterizar uma elite, segundo os critérios sob os quais o sociólogo a denomina. No entanto, a passagem de tais alunos pelo Colégio Aurora foi responsável pela formação, no nosso entender, de uma classe letrada na cidade de Caçador. A passagem dos filhos de 
imigrantes pelo Colégio Aurora mudaria, portanto, a trajetória dos egressos, e demarcaria uma fronteira entre os colonos e os antigos moradores da região Contestada, os chamados caboclos.

As fronteiras foram demarcadas na chegada dos primeiros imigrantes europeus vindos do Estado vizinho. Naquele momento, o outro foi identificado e, na sequência, os grupos se constituíram através de fronteiras inclusivas que se davam pelas crenças em comum, pela nacionalidade e pelo fato de compartilharem a mesma religião. A demarcação estabelecida se deu pela igualdade e pela homogeneização objetiva dos habitus de grupo ou de classe que resultam da homogeneidade das condições de existência, fazendo com que as práticas possam ser objetivamente acordadas longe de todo cálculo estratégico e de toda referência consciente (BOURDIEU, 1980, p. 98).

Ao analisar o espaço onde o Colégio Aurora foi construído percebemos as lutas de poder que eram verificadas no oeste catarinense, advindas da colonização. A demarcação de fronteiras pode ser percebida na construção de casas, igrejas e também, no caso analisado, da escola. Um lugar fronteiriço não só pelos muros que a cercam, mas, principalmente, em relação aos agentes sociais que a constituem.

A denominação agente utilizada por Bourdieu deixa explícito que, diferentemente dos atores que teriam um papel definido no espaço social, os agentes estão sempre em movimento, podendo estar na posição de dominantes e/ou dominados, dependendo do campo com que estão se relacionando (BOURDIEU, 1994, p. 173).

O campo cultural no momento da colonização do oeste catarinense funcionou como demarcador de posições: de um lado, o caboclo como o inferior, o não civilizado; de outro, o colono/imigrante como o civilizador, o dominante. Todo o campo é lugar de uma luta mais ou menos declarada pela definição dos princípios legítimos de divisão do campo. A questão da legitimidade surge da própria possibilidade desse "pôr-em-causa" (BOURDIEU, 1989).

A dinâmica dos campos, conforme Bourdieu nos permite pensar na constante rotatividade desses limites e entendemos, assim, que, num mesmo grupo, por exemplo, o dos italianos, existia frações de classe que se legitimavam também pelo volume de capitais, principalmente o econômico.

O capital econômico (bens, imóveis, posses) ajudaria na aquisição do capital cultural e o habitus do colono italiano ia se modificando dentro das salas do imponente prédio de madeira do bairro Santelmo. Os alunos do Aurora estavam sendo formados por uma cultura escolar que lhes garantiria uma trajetória distinta da de seus pais, dentro daquele espaço social.

O espaço social é um espaço multidimensional, conjunto aberto de campos relativamente autônomos, quer dizer, subordinados quanto ao seu funcionamento e às suas transformações, de modo mais ou menos firme e mais ou menos direto, ao campo de produção econômica (BOURDIEU,1989).

Para o sociólogo francês, o espaço social permite duas formas de deslocamentos: o vertical e o transversal. $O$ deslocamento vertical acontece no mesmo campo, caracterizando-se pela modificação de volume de capital. Diferentemente, o deslocamento transversal pressupõe a passagem para um outro campo, através da reconversão de uma espécie de capital em outra ou de uma subespécie de capital econômico ou de capital cultural em uma outra. Por exemplo, de fazendeiro para industrial, ou de uma cultura literária ou histórica para uma cultura econômica (BOURDIEU, 2007).

Para muitos alunos, o Colégio Aurora representou a reconversão do capital econômico em capital cultural, ocasionando um deslocamento transversal. Muitos tornaram-se professores, outros advogados e contadores. 
No entanto, não foi somente a reconversão de capital a responsável por tal mudança. Muitos alunos imigrantes não tinham condições financeiras de estudar no Colégio e garantiram sua estada através de uma bolsa de estudos, com a qual o alunobolsista tinha tarefas a cumprir, como limpar, cozinhar e trabalhar na secretaria. Mesmo assim conseguiram mudar sua trajetória, o que se explica pela condição do agente que, não sendo um ator, não está fadado a ocupar um papel predeterminado no espaço social.

Essa educação também foi responsável pela interiorização de certos comportamentos que passaram a compor o habitus dos agentes em estudo. Bourdieu vê o habitus como"sistemas de disposições duráveis e transmissíveis, estruturas estruturadas predispostas a funcionar como estruturas estruturantes, como princípios geradores e organizadores de práticas e de representações" (BOURDIEU, 1980, p.89).

$\mathrm{O}$ colégio Aurora inculcaria nos seus alunos um habitus secundário, já que a aquisição do habitus primário se daria na própria família. As estruturas estruturantes seriam transmitidas na socialização secundária, própria das instituições educacionais. Essas disposições que compõem o habitus dos agentes podem ser verificadas nos gostos, nas escolhas, e também na hexis corporal, que é o habitus impresso no corpo. As práticas geradas pelo habitus são processos inconscientes que se manifestam sem uma organização anterior.

A passagem desses alunos pelo Colégio Aurora contribuiu, sobretudo, para o aprimoramento do "capital cultural" de cada um. Segundo Bourdieu, o capital cultural pode existir de três formas: no estado incorporado, sob a forma de disposições duráveis do organismo; no estado objetivado, sob a forma de bens culturais; e no estado institucionalizado, sob a forma de objetivação conquistada, por exemplo, pelas trajetórias escolares.

Assim, o Colégio Aurora favoreceu a conquista e a ampliação de capital cultural no estado institucionalizado, através da aquisição de diplomas, com os quais os alunos teriam legitimidade para conseguir uma posição privilegiada no espaço social da cidade.

\section{Considerações}

Este artigo analisou a influência do Colégio Aurora para a formação da cidade de Caçador, Santa Catarina, nos anos 1930. Como vimos a emancipação política da cidade foi viabilizada pela criação do educandário.

A política de nacionalização do ensino forçou a venda da instituição para a Congregação dos Irmãos Maristas em 1938. No entanto, a pesquisa não verificou uma postura étnica por parte dos diretores. Pelo contrário, a abertura do Tiro de Guerra e de uma escola de Instrução Militar demonstrou o alinhamento com a política nacionalizadora.

A distinção do colégio naquele contexto histórico e social é resultado do trabalho do casal de italianos Dante e Albina Mosconi e sua formação acadêmica diferenciada. A criação do colégio Aurora garantiu a toda uma geração de crianças e adolescentes o acesso aos conhecimentos escolares em níveis primário e secundário, tão elitizados no Brasil e em Santa Catarina até os anos 1950. Foi através do capital escolar que muitos filhos de imigrantes puderam mudar suas trajetórias de vida, possibilitando um deslocamento em sua condição de agricultor.

Na dissertação de mestrado estudamos de forma aprofundada a clientela do colégio, e conseguimos perceber a ausência dos chamados caboclos nas salas de aula do Colégio Aurora. Esta ausência reproduziu o perfil socioeconômico da cidade que se formava. A impossibilidade de uma vaga vetou-lhes a conclusão de seus estudos em nível secundário, ficando restritos aos ensinamentos das escolas isoladas. Os formandos do Colégio Aurora, 
ao contrário, conseguiram bons ofícios, que possibilitaram certa distinção no espaço social caçadorense.

A ausência dos caboclos nas salas de aula do Colégio também foi verificada por outra minoria: as mulheres. A invisibilidade das mulheres pode ser questionada, pois se sabia que o colégio era misto; entretanto, os poucos documentos que encontramos registram o nome de apenas duas mulheres, mesmo no Curso Normal que, na década de trinta, no Brasil, já apresentava uma maior concentração feminina. Nas entrevistas que realizamos, elas também não aparecem. Há carência de documentos institucionais da época em que o colégio foi administrado pelo casal de italianos, para alguns entrevistados estes documentos provavelmente foram perdidos nas enchentes que assolaram o meio oeste, nas décadas de 30 e 40.

Mesmo com a escassez de fontes institucionais, a pesquisa demonstrou a importância deste educandário para a História da Educação de Santa Catarina e, principalmente, do meio-oeste catarinense. Em 1930, em tempos de nacionalização do ensino, este educandário foi criado e administrado por um casal de italianos que conseguiu implantar três cursos de nível secundário, tão raros nas escolas brasileiras na primeira metade do século XX.

\section{Referências}

AZZI, Riolando. História da educação católica no Brasil: a expansão da obra de Champagnat no Brasil, v.3. São Paulo: Secretariado Interprovincial Marista, 1999.

BARRICHELLO, Ângelo. Entrevista concedida a Ana Laura Tridapalli e Fernando Leocino da Silva. 2006.

BICUDO,J. De C. O ensino secundário no Brasil a sua atual Legislação. São Paulo: DEDALUS, 1931.

BITTENCOURT, Circe M. F. Livro didático e conhecimento histórico: uma história do saber escolar. Universidade de São Paulo, 1993. Tese de doutoramento apresentada ao Departamento de História da Faculdade de Filosofia, Letras e Ciências Humanas da USP.

BOURDIEU, Pierre. A Distinção: crítica social do julgamento. São Paulo: Edusp; Porto Alegre: Zouk, 2007.

La noblesse d'État. Grandesécoleset esprit de corps, 1989.

La reproduction. Paris: Ed. de Minuit,1970.

. Le senspratique. Paris: Ed. de Minuit,1980.

O Poder Simbólico. Lisboa :Difel, 1989.

Raisons pratiques. 1994

CAMPOS, Cyntia Machado. Controle e Normatização de Condutas em Santa Catarina (1930-1945). 1992. Dissertação (mestrado) - Pontifícia UniversidadeCatólica de São Paulo.

COLÉGIO Aurora. O Comércio. Porto União, n 23, 10 dez. 1933 
DANIEL, Leziany Silveira; DAROS, Maria das Dores; Universidade Federal de Santa Catarina. A formação de professores em Santa Catarina nas décadas de 30 e 40 entre o discurso da missão e o centralismo burocrático. Florianópolis, 1999. 48f.

FÁVERI, Marlene de. Memórias de uma (outra) guerra: cotidiano e medo durante a Segunda Guerra em Santa Catarina. 2.ed. Florianópolis: Ed. da UFSC; Itajaí: Ed. da Univali, 2005.

FAORO, Ernesto. Entrevista concedida a Ana Laura Tridapalli e Fernando Leocino da Silva. 2007.

HORTA, José Silvério Baia. O Hino, O sermão e a ordem do dia; regimeautoritário e a educação no Brasil. Rio de Janeiro: Ed. UFRJ, 1994.

O COMÉRCIO. Porto União. ? Mar. 1932. p.01

RAISEL, Izaltino. A Era Mosconi na história de Caçador: estudo sobre a vida e a obra do casal Dante e Albina Mosconi no campo da Educação - Marco na História de Caçador: FEARPE, 1984.

RELATÓRIOS da InspetoriaFederaljunto ao GinásioAurora. 1938-1945

RELATÓRIO informativo de visita do Irmão Provincial a Florianópolis - 1938

ROMANELLI, Otaiza de Oliveira. Historia da educação no Brasil (1930/1973). 7. ed. Petrópolis: Vozes, 1985.

SANTA CATARINA. Decreto-Lei $\mathbf{n}^{\circ}$ 436, de 7 de novembro de 1933. Equipara à Escola Normal Catarinense, o curso Normal do Colégio Aurora; de Santelmo.

SANTA CATARINA. Decreto-Lei $\mathbf{n}^{\circ} \mathbf{1 6 1 7}$, de $1^{\circ}$ de outubro de 1928 . Determina as condições em que poderão ser equiparadas à Escola Normal do Estado os estabelecimentos de ensino particular.

SEYFERTH, Giralda. Nacionalismo e identidade étnica. Florianópolis: Fundação Catarinense de Cultura, 1981.

THOMÉ, Nilson. Colégio Aurora - uma visão histórica. Caçador: Prefeitura/INCON Edições, 1993.

TRIDAPALLI, Ana Laura. Bons cristãos e virtuosos cidadãos: cultura escolar Maristea no Ginásio Aurora (1938-1945). 2006. 86f. Trabalho de conclusão de curso (Graduação) Universidade do Estado de Santa Catarina.

VIRTUOSO, Tatiane dos Santos. Disputas de Identidades : A nacionalização do ensino em meio aos Ítalo- Brasileiros (1900-1930).Dissertação de Mestrado - Universidade Federal de Santa Catarina - UFSC. 2008.

\footnotetext{
${ }^{1}$ Este trabalho é resultado de uma pesquisa de pós graduação financiada pelo Conselho Nacional de Desenvolvimento Científico e Tecnológico - CNPq através de uma bolsa de formação de pesquisador de Mestrado

2 O curso de Guarda-Livros era o nome dado ao curso Comercial; o curso Normal passou a funcionar no Colégio Aurora em 1930.

${ }^{3}$ O irmão Tomaz de Vilanova foi diretor do Colégio Aurora durante os anos, 1938-1942, em pleno Estado Novo. Ele era francês. Esta questão da aliança entre a Congregação dos Irmãos Maristas e o governo de
} 
Nereu Ramos foi aprofundada no trabalho: TRIDAPALLI, Ana Laura. Bons cristãos e virtuosos cidadãos: cultura escolar Marista no Ginásio Aurora (1938-1945). 2006. 86f. Trabalho de conclusão de curso (Graduação) - Universidade do Estado de Santa Catarina.

${ }^{4}$ A turma iniciou a formação em 1929 antes mesmo da oficialização do Curso.

${ }^{5}$ Entrevista concedida em Caçador, out. 2007.

${ }^{6}$ RELATÓRIO informativo de visita do Irmão Provincial a Florianópolis - 1938.

${ }^{7}$ Em Santa Catarina, na década de 1930, existiam somente seis escolas normais secundárias. As Escolas Normais de Florianópolis e Lages eram gratuitas. As quatro particulares estavam assim localizadas: uma em Florianópolis, anexa ao Colégio Coração de Jesus; outra anexa ao Colégio Santos Anjos, em Porto União; a terceira anexa ao Colégio Aurora, em Caçador, e a quarta anexa ao Colégio Coração de Jesus, em Canoinhas (DANIEL; DAROS,1999, p.19).

Recebido: fev-13 Aprovado: mai-14 